\title{
The dynamics of organizational identity
}

Publicado originalmente na Revista Human Relations, 2002, 55: 989-1018 1

Mary Jo Hatch and Majken Schultz*

\begin{abstract}
While many organizational researchers make reference to Mead's theory of social identity, none have explored how Mead's ideas about the relationship between the "I" and the "me" might be extended to identity processes at the organizational level of analysis. In this paper we define organizational analogues for Mead's "I" and "me" and explain how these two phases of organizational identity are related. In doing so we bring together existing theory concerning the links between organizational identities and images, with new theory concerning how reflection embeds identity in organizational culture and how identity expresses cultural understandings through symbols. We offer a model of organizational identity dynamics built on four processes linking organizational identity to culture and image. While the processes linking identity and image (mirroring and impressing) have been described in the literature before, the contribution of this paper lies in articulation of the processes linking identity and culture (reflecting and expressing), and of the interaction of all four processes working dynamically together to create, maintain and change organizational identity. We discuss the implications of our model in terms of two dysfunctions of organizational identity dynamics: narcissism and loss of culture.
\end{abstract}

Keywords: Organizational identity, Organizational image, Organizational culture, Organizational narcissism, Identity processes, Identity dynamics.

\section{The dynamics of organizational identity}

In a world of increased exposure to critical voices, many organizations find creating and maintaining their identities problematic (Albert \& Whetten, 1985; Cheney \&

\footnotetext{
${ }^{1}$ Reprinted by permission of Sage Publications Ltd from Author, Title, Copyright ((C) The Travistock Institute, 2002)

* McIntire School of Commerce, University of Virginia. E-mail: mjhatch@virginia. edu. CopenhagenBusinessSchool
} 
Christensen, 2001). For example, the media is taking more and more interest in the private lives of organizations and in exposing any divergence it finds between corporate images and organizational actions. This exposure is fed by business analysts who now routinely supplement economic performance data with evaluations of internal business practices such as organizational strategy, management style, organizational processes and corporate social responsibility (Fombrun 1996; Fombrun \& Rindova 2000). As competition among business reporters and news programs increases, along with growth in attention to business on the internet, this scrutiny is likely to intensify (Deephouse 2000). In addition, when employees are also customers, investors, local community members and/or activists, as they frequently are in this increasingly networked world, they carry their knowledge of internal business practices beyond the organization's boundaries and thus add to organizational exposure.

Exposure is not the only identity-challenging issue faced by organizations today. Organizational efforts to draw their external stakeholders into a personal relationship with them allow access that expands their boundaries and thereby changes their organizational self-definitions. For instance, just-in-time inventory systems, value chain management and e-business draw suppliers into organizational processes, just as customer service programs encourage employees to make customers part of their everyday routines. This is similar to the ways in which investor- and community-relations activities make the concerns of these stakeholder groups a normal part of organizational life. However, not only are employees persuaded to draw external stakeholders into their daily thoughts and routines, but these same external stakeholders are encouraged to think of themselves and behave as members of the organization. For example, investors are encouraged to align their personal values with those of the companies to which they provide capital (e. g., ethical investment funds), while customers who join customer clubs are invited to consider themselves organizational members. Suppliers, unions, communities and regulators become partners with the organization via similar processes of mutual redefinition. Combined, these forces give stakeholder groups greater and more intimate access to the private face of the firm than they have ever experienced before.

One implication of increased access to organizations is that organizational culture, once hidden from view, is now more open and available for scrutiny to anyone interested in a company. By the same token, increased exposure means that organizational employees hear more opinions and judgments about their organization from stakeholders (i. e., they encounter more images of their organization with greater frequency). Our departure point for this paper lies in the idea that the combined forces of access and exposure put pressure on organizational identity theorists to account for the effects of both organizational culture as the context of internal definitions of organizational identity, and organizational images as the site of external definitions of organizational identity, but most especially to describe the processes by which these two sets of definitions influence one another. 
Following Hatch \& Schultz (1997; 2000), we argue that organizational identity needs to be theorized in relation to both culture and image in order to understand how internal and external definitions of organizational identity interact. In this paper we will model four processes that link identity, culture and image (see figure 1) - mirroring (the process by which identity is mirrored in the images of others), reflecting (the process by which identity is embedded in cultural understandings), expressing (the process by which culture makes itself known through identity claims), and impressing (the process by which expressions of identity leave impressions on others). While mirroring and impressing have been presented in the literature before, our contribution lies in specifying the processes of expressing and reflecting and in articulating the interplay of all four processes that together construct organizational identity as an ongoing conversation or dance between organizational culture and organizational images.

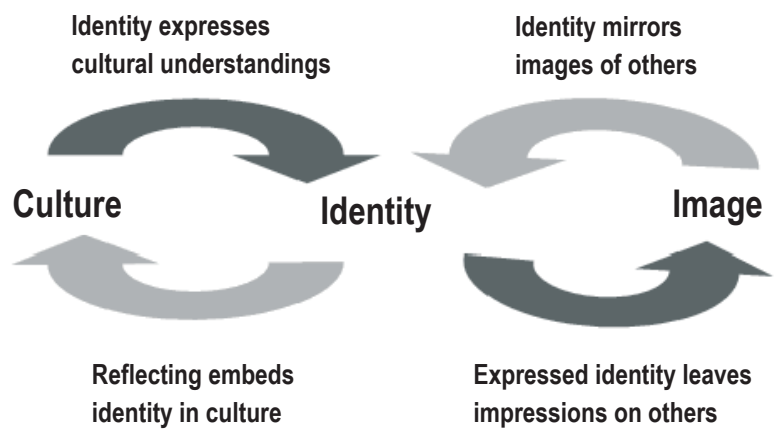

Figure 1. The Organizational Identity Dynamics Model

\section{Defining organizational identity}

Much of the research on organizational identity builds on the idea that identity is a relational construct formed in interaction with others (e. g., Albert \& Whetten, 1985; Ashforth \& Mael, 1989; Dutton \& Dukerich, 1991). For example, Albert and Whetten (1985:273, citing Erickson 1968) described the process of identity formation:

... in terms of a series of comparisons: (1) outsiders compare the target individual with themselves; (2) information regarding this evaluation is conveyed through conversations between the parties ("polite boy," "messy boy") and the individual takes this feedback into account by making personal comparisons with outsiders, which then; (3) affects how they define themselves.

Albert and Whetten concluded on this basis "that organizational identity is formed by a process of ordered inter-organizational comparisons and reflections upon them over time. " Gioia (1998; Gioia, Schultz \& Corley, 2000) traced Albert and Whetten's foundational ideas to the theories of Cooley (1902), Mead (1934) and Goffman 
(1959). While Cooley's idea of the "looking glass self" and Goffman's impression management have been well-represented in the literature that links organizational identity to image (e. g., Dutton \& Dukerich, 1991; Ginzel, Kramer \& Sutton, 1993), Mead's ideas about the "I" and the "me" have yet to find their way into organizational identity theory.

The idea of identity as a relational construct is encapsulated by Mead's (1934:135) proposition that identity (the self):

$\ldots$ arises in the process of social experience and activity, that is, develops in the given individual as a result of his relations to that process as a whole and to other individuals within that process.

Here Mead made clear that identity should be viewed as a social process and went on to claim that it has two "distinguishable phases," one he called the "I" and the other the "me". According to Mead (1934:175):

The "I" is the response of the organism to the attitudes of the others; the "me" is the organized set of attitudes of others which one himself assumes. The attitudes of the others constitute the organized "me," and then one reacts toward that as an "I".

In Mead's theory, the "I" and the "me" are simultaneously distinguishable and interdependent. They are distinguishable in that the "me" is the self a person is aware of, while the "I" is "something that is not given in the "me" (Mead 1934:175). They are interrelated in that the "I" is "the answer which the individual makes to the attitude which others take toward him when he assumes an attitude toward them" (Mead 1934:177). "The 'I' both calls out the 'me' and responds to it. Taken together they constitute a personality as it appears in social experience” (Mead 1934:178).

While it is clear that Albert and Whetten's (1985) formulation of organizational identity is based in an idea similar to Mead's definition of individual identity, Albert and Whetten did not make explicit how the organizational equivalents of Mead's "I" and "me" were involved in organizational identity formation. Before turning to this matter, we need to address the perennial question of whether individual level theory can be generalized to organizational phenomena.

\section{Generalizing from Mead}

In relation to the long-standing problem of the validity of borrowing concepts and theories defined at the individual level of analysis and applying them to the organization, Jenkins (1996:19) argued that, where identity is concerned:

... the individually unique and the collectively shared can be understood as similar (if not exactly the same) in important respects ... and the processes by which they are produced, reproduced and changed are analogous. 
While Jenkins took on the task of describing how individual identities are entangled with collectively shared identities (see also Brewer \& Gardner, 1996, on this point), in this paper we focus on the development of identity at the collective level itself, which Jenkins argued can be described by processes analogous to those defined by Mead's individual level identity theory.

Jenkins (1996) noted that the tight coupling that Mead theorized between the "I" and the "me" renders conceptual separation of the social context and the person analytically useful but insufficient to fully understand how identity is created, maintained and changed. Building on Mead, Jenkins (1996:20, emphasis in original) argued that:

... the 'self' [is] an ongoing and, in practice simultaneous, synthesis of (internal) self-definition and the (external) definitions of oneself offered by others. This offers a template for the basic model ... of the internal-external dialectic of identification as the process whereby all identities - individual and collective - are constituted.

Jenkins then suggested that Mead's ideas might be taken further by articulating the processes that synthesize identity from the raw material of internal and external definitions of the organization. The challenge that we take up in this paper is to find organizational analogues for Mead's "I" and "me" and to articulate the processes that bring them together to create, sustain and change organizational identity. We begin by searching for ideas related to organizational identity formation processes in the organizational literature.

Drawing on work in social psychology (e. g., Tajfel \& Turner, 1979; Tedeshi, 1981; Brewer \& Gardner 1996) and sociology (Goffman, 1959), a few organizational researchers have given attention to the processes defining identity at the collective or organizational level. For example, as we will explain in more detail below, Dutton \& Dukerich (1991) pointed to the process of mirroring organizational identities in the images held by their key stakeholders, while Fombrun and Rindova (2000; see also Gioia \& Thomas, 1996) discussed the projection of identity as a strategic means of managing corporate impressions. However, although these processes are part of identity construction, they focus primarily on the "me" aspect of Mead's theory. Thus they do not, on their own, provide a full account of the ways in which Mead's "I" and "me" (or Jenkins' internal and external self-definitions) relate to one another at the organizational level of analysis.

It is our ambition in this paper to provide this fuller account using analogous reasoning to explicate Mead's "I" and " $m e$ " in relation to the phenomenon of organizational identity and to relate the resultant organizational "I" and "me" in a processbased model describing the dynamics of organizational identity. To address the question - How do the organizational analogues of Mead's "I" and "me" interact to form organizational identity? - requires that we first specify the organizational analogues of Mead's "I" and "me". We now turn our attention to this specification and invite you to refer to figure 2 as we explain what we mean by the organizational "I" and "me". 


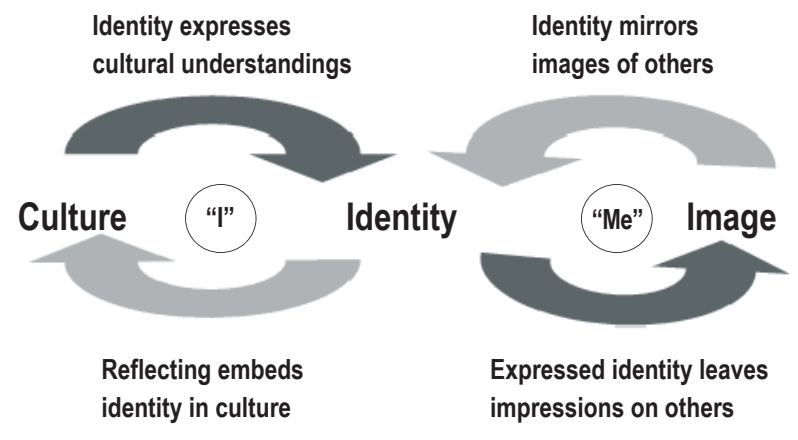

Figure 2. How the organizational "I" and me "are" constructed within the process of the Organizational Identity Dynamics Model

\section{Organizational analogues of Mead's "I" and "Me"}

Dutton and Dukerich (1991:550) defined organizational image as "what [organizational members] believe others see as distinctive about the organization. "In a later article Dutton, Dukerich and Harquail (1994) restricted this definition of organizational image by renaming it "construed organizational image". Under either label, the concept comes very close to Mead's definition of the "me" as "an organized set of attitudes of others which one himself assumes". However, the images formed and held by the organization's "others" are not defined by what insiders believe about what outsiders perceive, but by the outsiders' own perceptions (their images) and it is our view that these organizational images are brought directly into identity processes by access and exposure, as was explained in the introduction to this paper.

It is our contention that the images offered by others (Jenkins's external definitions of the organization) are present to identity processes in ways that generally have been overlooked by organizational identity researchers who adopt Dutton and Dukerich's definition of organizational image, though not by strategy, communication or marketing researchers (e. g., Fombrun \& Rindova, 2000; Christensen \& Cheney, 2001; Dowling 2001, to name only a few). Specifically, what organizational researchers have overlooked is that others' images are part of, and to some extent independent of, organizational members who construct their mirrored images from them. For this reason we define organizational image, following practices in strategy, communication and marketing, as the set of views on the organization held by those who act as the organization's “others". By analogy, the organizational "me” results when organizational members assume the images that the organization's “others" (e. g., its external stakeholders) form of the organization. What Dutton and Dukerich (1991) referred to as organizational image, and Dutton, Dukerich and Harquail (1994) as construed organizational image, we therefore subsume into our notion of the organizational "me" as that which is generated during the process of mirroring (see the discussion of mirroring in the following section of the paper). 
Defining the "me" of Mead's theory in relation to organizational identity is much easier than defining the "I". By application of Mead's theorizing, the organizational "I" must be something of which the organization is unaware (otherwise it would be part of the organizational "me") and "something that is not given in the "me". In addition, the "I" must be responsive to the attitudes of others. We believe that culture is the proper analogy to Mead's "I" in that Mead's descriptors of the "I" fit the organizational culture concept quite closely. First, organizational culture generally operates beneath awareness in that it is regarded by most culture researchers as being more tacit than explicit (e. g., Krefting \& Frost, 1985; Hatch \& Schultz 2000). Second, culture is not given by what others think or say about it (though these artifacts can be useful indicators), but rather resides in deep layers of meaning, value, belief and assumption (e. g., Schein 1985; 1992; Hatch 1993; Schultz 1994). And third, as a context for all meaning-making activities (e. g., Czarniawska, 1992; Hatch \& Schultz, 2000) culture responds (and shapes responses) to the attitudes of others.

For the purposes of this paper, organizational culture is defined as the tacit organizational understandings (e. g., assumptions, beliefs and values) that contextualize efforts to make meaning, including internal self-definition. Just as organizational image forms the referent for defining the organizational "me", it is with reference to organizational culture that the organizational "I" is defined.

\section{The "conceptual minefield" of culture and identity}

As can be seen from the discussion above, culture and identity are closely connected and the early literature on organizational identity often struggled to explain how the two might be conceptualized separately. For example, Albert and Whetten (1985: 2656) reasoned:

Consider the notion of organizational culture ... Is culture part of organizational identity? The relation of culture or any other aspect of an organization to the concept of identity is both an empirical question (does the organization include it among those things that are central, distinctive and enduring) and a theoretical one (does the theoretical characterization of the organization in question predict that culture will be a central, distinctive, and an enduring aspect of the organization).

Fiol, Hatch and Golden-Biddle (1998:56) took the relationship between culture and identity a step further in stating that: "An organization's identity is the aspect of culturally embedded sense-making that is [organizationally] self-focused". Hatch and Schultz (2000) in their examination of the overlapping meanings ascribed to organizational culture and identity, stated that the two concepts are inextricably interrelated by the fact that they are so often used to define one another. A good example of the conflation of these terms comes from Dutton and Dukerich (1991:546): 
... an organization's identity is closely tied to its culture because identity provides a set of skills and a way of using and evaluating those skills that produce characteristic ways of doing things ... "cognitive maps" like identity are closely aligned with organizational traditions.

The early conflation of concepts does not mean, however, that the two concepts are indistinguishable, nor that it is unnecessary to make the effort to distinguish them when defining and theorizing organizational identity. Using the method of relational differences that they built on Saussurean principles, Hatch and Schultz (2000: 24-26) distinguished between identity and culture using three dimensions along which the two concepts are differently placed in relation to one another: textual/contextual, explicit/ tacit and instrumental/emergent. They pointed out that while each of the endpoints of these dimensions can be used to define either concept, the two concepts are distinguishable by culture's being relatively more easily placed in the conceptual domains of the contextual, tacit and emergent than is identity which, when compared to culture, appears to be more textual, explicit and instrumental.

\section{Defining organizational identity in relation to culture and image}

Reasoning by analogy from Mead's theory, our position is that if organizational culture is to organizational identity what the "I" is to individual identity, it follows that, just as individuals form their identities in relation to both internal and external definitions of self, organizations form theirs in relation to culture and image. And even if internal and external self-definitions are purely analytical constructions, these constructions and their relationships are intrinsic to raising the question of identity at all. Without recognizing differences between internal and external definitions of self, or by analogy culture and image, we could not formulate the concepts of individual or organizational identity (i. e., who we are vs. how others see us). Therefore, we have taken culture and image as integral components of our theory of organizational identity dynamics.

In the remainder of the paper we will argue that organizational identity is neither wholly cultural nor wholly imagistic, it is instead constituted by a dynamic set of processes that interrelate the two. We will now investigate these processes and explain how they operate, first articulating them separately, and then examining them as an interrelated and dynamic set.

\section{Organizational identity processes and their dynamics}

In this section we will define the processes by which organizational identity is created, maintained and changed and explain the dynamics by which these processes are interrelated. In doing so we will also explain how organizational identity is simultaneously linked with images held by the organization's "others" and with cultural understandings. The processes and their relationships with culture, identity and image are illustrated in figure 2 which presents our organizational identity dynamics model. The 
model diagrams the identity-mediated relationship between stakeholder images and cultural understandings in two ways. First, the processes of mirroring organizational identity in stakeholder images and reflecting on "who we are" describe the influence of stakeholder images on organizational culture (the lighter gray arrows in figure 2). Second, the processes of expressing cultural understandings in identity claims and using these expressions of identity to impress others describe the influence of organizational culture on the images of the organization that others hold (the darker gray arrows in the figure). As organizational analogues for the "I" and the "me", the links between culture and image in the full model diagram the interrelated processes by which internal and external organizational self-definitions construct organizational identity.

\section{Identity mirrors the images of others}

In their study of the Port Authority of New York and New Jersey, Dutton and Dukerich (1991) found that when homeless people congregated in the Port Authority's bus and train stations, the homeless problem became the Port Authority's problem in the eyes of the community and the local media. Dutton and Dukerich showed how the negative images of the organization encountered in the community and portrayed in the press encouraged the Port Authority to take action to correct public opinion. They suggested that the Port Authority's organizational identity was reflected in a mirror held up by the opinions and views of the media, community members and other external stakeholders in relation to the problem of homelessness and the Port Authority's role in it. The images the organization saw in this metaphorical mirror were contradicted by how it thought about itself (i. e., its identity). This led the Port Authority to act on behalf of the homeless in an effort to preserve its identity and to change its organizational image.

On the basis of their study Dutton and Dukerich (1991) claimed that the opinions and reactions of others affect identity through mirroring and further suggested that mirroring operates to motivate organizational members to get involved in issues that have the power to reduce public opinion of their organization. Thus, Dutton and Dukerich presented a discrepancy analysis, suggesting that, if organizational members see themselves more or less positively than they believe that others see them, they will be motivated by the discrepancy to change either their image (presumably through some action such as building homeless shelters) or their identity (to align with what they believe others think of them). These researchers concluded that we "might better understand how organizations behave by asking where individuals look, what they see, and whether or not they like the reflection in the mirror. " (1991:551). In regard to defining the mirroring process in terms that link identity and image, Dutton and Dukerich (1991: 550) stated that:

... what people see as their organization's distinctive attributes (its identity) and what they believe others see as distinctive about the organization (its image) constrain, mold, and fuel interpretations ... Because image and identity are constructs that organization mem- 
bers hold in their minds, they actively screen and interpret issues like the Port Authority's homelessness problem and actions like building drop-in centers using these organizational reference points.

We argue that the mirroring process has more profound implications for organizational identity dynamics than is implied by Dutton and Dukerich's discrepancy analysis. As we argued in developing our organizational analogy to Mead's "me", we believe that external stakeholder images are not completely filtered through the perceptions of organizational members (as Dutton \& Dukerich 1991 suggested in the quote above). Instead, traces of the stakeholders' own images leak into organizational identity, particularly given the effects of access discussed in the introduction to this paper by which external stakeholders cross the organizational boundary. Furthermore, in terms of the mirroring metaphor, the images others hold of the organization are the mirror, and as such are intimately connected to the mirroring process.

The notion of identity is not just about reflection in the mirroring process, it is also about self-examination. In addition to describing mirroring, the Port Authority case also showed how negative images prompted an organization to question its self-definition. In making their case that orgaioznatonal identities are adaptively unstable, Gioia, Schultz and Corley (2000:67) made a similar point: "Image often acts as a destabilizing force on identity, frequently requiring members to revisit and reconstruct their organizational sense of self. " As we have argued already, matters of organizational self-definition are also matters of organizational culture.

\section{Reflecting embeds identity in organizational culture}

Organizational members not only develop their identity in relation to what others say about them, but also in relation to who they perceive they are. As Dutton and Dukerich (1991) showed, the Port Authority did not simply accept the images of themselves that they believed others held, they sought to alter these images (via the process of impressing others via identity expressions, to which we will return in a moment). We claim that they did this in service to a sense of themselves (their organizational "I") that departed significantly from the images they believed others held. In our view, what sustained this sense of themselves as different from the images they saw in the mirror is their organizational culture.

We claim that once organizational images are mirrored in identity they will be interpreted in relation to existing organizational self-definitions that are embedded in cultural understanding. When this happens, identity is reinforced or changed through the process of reflecting on identity in relation to deep cultural values and assumptions that are activated by the reflection process. We believe that reflecting on organizational identity embeds that identity in organizational culture by triggering or tapping into the deeply held assumptions and values of its members which then become closely associated with the identity and its various manifestations (e. g., logo, name, identity statements). 
Put another way, we see reflexivity in organizational identity dynamics as the process by which organizational members understand and explain themselves as an organization. But understanding is always dependent upon its context. As Hatch (1993:686-7) argued, organizational culture provides context for forming identities as well as for taking action, making meaning and projecting images. Thus when organizational members reflect on their identity, they do so with reference to their organization's culture and this embeds their reflections in tacit cultural understandings, or what Schein (1985/1992) referred to as basic assumptions and values. This embedding, in turn, allows culture to imbue identity artifacts with meaning, as was suggested by Dewey (1934).

According to Dewey (1934), aspects of meaning reflectively attained gradually become absorbed by objects (cultural artifacts), that is, we come to perceive objects as possessing those meanings experience adds to them. It follows that when meanings are expressed in cultural artifacts, the artifacts then carry that meaning from the deep recesses of cultural understanding to the cultural surface. The meaning-laden artifacts of a culture thereby become available to self-defining, identity forming processes.

Following Dewey, we therefore further argue that whenever organizational members make explicit claims about what the organization is, their claims carry with them some of the cultural meaning in which they are embedded. In this way culture is embodied in material artifacts (including identity claims as well as other identity artifacts such as logo, name, etc.) that can be used as symbols to express who or what the organization is, thus contributing culturally produced, symbolic material to organizational identity. So it is that cultural understandings are carried, along with reflections on identity, into the process of expressing identity.

\section{Identity expresses cultural understandings}

One way an organization makes itself known is by incorporating its organizational reflections in its outgoing discourse, that is, the identity claims referred to above allow organizational members to speak about themselves as an organization to themselves but also to others. Czarniawska's (1997) narratives of institutional identity are an example of one form such organizational self-expression could take. But institutional identity narratives are only one instance of the larger category of cultural self-expression as we define it. In more general terms, cultural self-expression includes any and all references to collective identity (Brewer \& Gardner, 1996; Jenkins, 1996).

When symbolic objects are used to express an organization's identity their meaning is closely linked to the distinctiveness that lies within any organizational culture. As Hatch (1993, following Ricoeur) explained, artifacts become symbols by virtue of the meanings that are given to them. Thus, even though its meaning will be re-interpreted by those that receive it, when a symbol moves beyond the culture that created it some of its original meaning is still embedded in and carried by the artifact. The explanation for this given by Hatch rests in the hermeneutics of interpretation through which every text (a category that includes symbolic objects and anything else that is interpreted) 
is constituted by layered interpretations and thus carries (a portion of) its history of meaning within it.

Based on the reasoning presented above, it is our contention that organizational cultures have expressive powers by virtue of the grounding of the meaning of their artifacts in the symbols, values and assumptions that cultural members hold and to some extent share. This connection to deeper patterns of organizational meaning is what gives cultural explication of assumptions in artifacts their power to communicate believably about identity. Practices of expression such as corporate advertising, corporate identity and design programs (e. g., Olins, 1989), corporate architecture (e. g., Berg \& Kreiner, 1990), corporate dress (e. g., Rafaeli \& Pratt, 1993; Pratt \& Rafaeli 1997), and corporate rituals (Rosen, 1988; Schultz, 1991), when they make use of an organizational sense of its cultural self (its organizational "I") as a referent, help to construct organizational identity through culturally contextualized self-expression.

Part of the explanation for the power of artifacts to communicate about organizational identity lies in the emotional and aesthetic foundations of cultural expression. Philosophers have linked expression to emotion (e. g. Croce, 1909/1995; Scruton, 1997: 140-170) and also to intuition (Croce, 1909/1995; Collingwood, 1958; Dickie, 1997). For instance, referring to Croce, Scruton (1997:148) claimed that when a work of art "has 'expression,' we mean that it invites us into its orbit. " These two ideas - of emotion, and of an attractive force inviting us into its orbit - suggest that organizational expressions draw stakeholders to them by emotional contagion or by their aesthetic appeal. As Scruton (1997:157) put it: "The expressive word or gesture is the one that awakens our sympathy". We argue that when stakeholders are in sympathy with expressions of organizational identity, their sympathy connects them with the organizational culture that is carried in the traces of identity claims. That sympathy and connection with organizational culture grounds the "we" (we regard this "we" as equivalent to the organizational "I") in a socially constructed sense of belonging that Brewer \& Gardner (1996) defined as part of collective identity.

However, organizational identity is not only the collective's expression of organizational culture. It is also a source of identifying symbolic material that can be used to impress others in order to awaken their sympathy by stimulating their awareness, attracting their attention and interest, and encouraging their involvement and support.

\section{Expressed identity leaves impressions on others}

In their work on corporate reputations, Rindova and Fombrun (1998) proposed that organizations project images to stakeholders and institutional intermediaries, such as business analysts and members of the press. In its most deliberate form identity is projected to others, for example, by broadcasting corporate advertising, holding press conferences, providing information to business analysts, creating and using logos, building corporate facilities, or dressing in the corporate style. Relating these projected images to organizational identity, Rindova and Fombrun (1998: 60) stated: 
Projected images reflect not only a firm's strategic objectives but also its underlying identity. Images that are consistent with organizational identity are supported by multiple cues that observers receive in interacting with firms.

Whereas strategic projection, or what others have called impression management (Pfeffer 1981; Ginzel, Kramer \& Sutton 1993), is a component of organizational identity dynamics, Rindova and Fombrun (1998) also noted that projection of organizational identity can be unintentional (e. g., communicated through everyday behavior, gestures, appearance, attitude):

Images are not projected only through official, management-endorsed communications in glossy brochures because organizational members at all levels transmit images of the organization.

Thus expressions of organizational culture can make important contributions to impressing others that extend beyond the managed or intended impressions created by deliberate attempts to convey a corporate sense of organizational identity. This concern for the impressions the organization makes on others brings us back from considerations of culture and its expressions (on the left side of figure 2) to concerns with image and its organizational influences (shown on the right side of the same figure).

Of course there are other influences on image beyond the identity the organization attempts to impress on others. For example, one of the determinants of organizational images that lies beyond the organization's direct influence (and beyond the boundaries of our identity dynamics model) is the projection of others' identities onto the organization, in the Freudian sense of projection. Assessments of the organization offered by the media and business analysts, and the influence of issues that arise around events such as oil spills or plane crashes, may be defined, partly or wholly, by the projections of others' identities and emotions onto the organization ("I feel bad about the oil spill in Alaska and therefore have a negative attitude toward the organization I hold responsible for the spill”). Thus, organizational efforts to impress others are tempered by the impressions those others take from outside sources. These external impressions are multiplied by the effects of organizational exposure that were discussed in the introduction to this paper because increased exposure means more outside sources producing more images to compete with those projected by the organization.

The influences of others will be counted or discounted by the organization when it chooses self-identifying responses to their images in the mirroring and reflecting processes that relate organizational image back to organizational culture. Having made these connections between organizational culture, identity and image, we are now ready to discuss the model of organizational identity dynamics shown in figure 2 in its entirety. 


\section{The dynamism of organizational identity processes and the role of power}

The way that we have drawn the identity dynamics model in figure 2 is meant to indicate that organizational identity occurs as the result of a set of processes that continuously cycle within and between cultural self-understandings and images formed by organizational "others". As Jenkins (1994:199) put it: "It is in the meeting of internal and external definitions of an organizational self that identity ... is created". Our model helps to specify the processes by which the meeting of internal and external definitions of organizational identity occurs and thereby to explain how organizational identity is created, maintained and changed. Based on this model, we would say that at any moment identity is the immediate result of conversation between organizational (cultural) self-expressions and mirrored stakeholder images, recognizing, however, that whatever is claimed by members or other stakeholders about an organizational identity will soon be taken up by processes of impressing and reflecting which feed back into further mirroring and expressing processes. This is how organizational identity is continually created, sustained and changed. It is also why we insist that organizational identity is dynamic -- the processes of identity do not end but keep moving in a dance between various constructions of the organizational self (both the organizational "I" and the organizational "me") and the uses to which they are put. This helps us to see that organizational identity is not an aggregation of perceptions of an organization resting in peoples' heads, it is a dynamic set of processes by which an organization's self is continuously socially constructed from the interchange between internal and external definitions of the organization offered by all organizational stakeholders who join in the dance.

A word on power might be beneficial at this point. Power suffuses our model in that any (or all) of the processes are open to more influence by those with greater power. For example, the choice of which cultural material to deliberately draw into expressions of organizational identity usually falls into the hands of those chosen by the most powerful members of the organization, such as when top management names a creative agency to design its logo or an advertising firm to help it communicate its new symbol to key stakeholders. When the powerful insist on the right to make final decisions regarding logo or advertising, the effects of power further infiltrate the dynamics of organizational identity. Another example, drawn from the other side of figure 2 , is the power that may be exercised over conflicting views of what stakeholder images mean for the organization's sense of itself. If powerful managers are unwilling to listen to the reports presented by market researchers or other members of the organization who have less influence than they do, the processes of mirroring and reflecting will be infiltrated by the effects of power. Of course not only can the powerful disrupt organizational identity dynamics, they can just as easily use their influence to enhance the dynamics of organizational identity by encouraging continuous interplay between all the processes shown in figure 2 . In any case, while we cannot explicitly model the effects of power due to their variety and complexity, we mark the existence of these influences for those who want to apply our work. We turn now to consideration of what happens when identity dynamics are disrupted. 


\section{Dysfunctions of organizational identity dynamics}

Albert \& Whetten (1985:269) proposed that disassociation between the internal and external definitions of the organization or, by our analogy to Mead, disassociation of the organizational "I" and "me", may have severe implications for the organization's ability to survive:

The greater the discrepancy between the ways an organization views itself and the way outsiders view it ..., the more the 'health' of the organization will be impaired (i. e. lowered effectiveness).

Following their lead it is our belief that, when organizational identity dynamics are balanced between the influences of culture and image, a healthy organizational identity results from processes that integrate the interests and activities of all relevant stakeholder groups.

However, a corollary to Albert and Whetten's proposition is that it is also possible for organizational identity dynamics to become dysfunctional in the psychological sense of this term. We argue that this happens when culture and images become disassociated - a problem that amounts to ignoring or denying the links between culture and images that the pressures of access and exposure, addressed earlier, make so noticeable. In terms of the organizational identity dynamics model, the result of such disassociations is that organizational identity may be constructed primarily in relation to organizational culture or stakeholder images, but not to both (more or less) equally. When this occurs, the organization is vulnerable to one of two dysfunctions: either narcissism or loss of organizational culture (see figure 3).

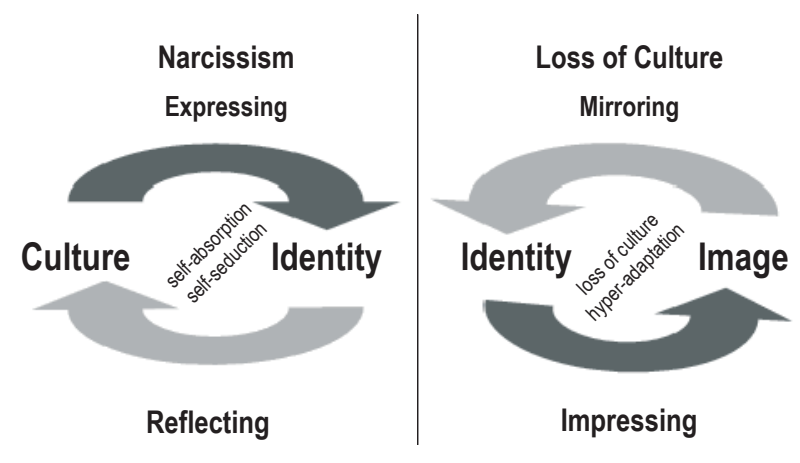

Figure 3. Sub-dynamics of the Organizational Identity Dynamics Model and their potential dysfunctions. 


\section{Organizational narcissism}

Within the organizational dynamics model the first dysfunction emerges from a construction of identity that refers exclusively or nearly exclusively to the organization's culture with the likely implication that the organization will lose interest and support from their external stakeholders. We believe that this is what happened to Royal Dutch Shell when it ignored heavy criticism from environmentalists, especially Greenpeace, concerned with the planned dumping of the Brent Spar oilrig into the North Sea. Shell's early responses to Greenpeace were based in Shell's engineeringdriven culture. This culture was insular and oriented toward the technical concerns of risk analysis supported by scientific data provided by the British government. Shell's framing of the Brent Spar issue caused them to ignore the symbolic effects of dumping the oilrig. The subsequent spread of negative images from activist groups to the general public and to Shell customers exemplifies one effect of exposure in which media generated and communicated images of activists tying themselves to the oilrig were repeatedly sent around the world. Shell's initial denials of guilt and refusals to dialogue with Greenpeace clearly fit the description of a dysfunctional identity dynamic: Shell's identity in the crisis was embedded in a culture that insulated the company's management from shifting external images, in this case shifting from bad to worse in a very short period of time.

As explained by Fombrun \& Rindova (2000) this incident, along with Shell's crisis in Nigeria, provoked considerable self-reflection within Shell (2000:78). The reflection then led to their giving attention to two-way communication and to their innovative Tell Shell program (an interactive website designed to solicit stakeholder feedback). Shell's subsequent careful monitoring of global stakeholder images of the corporation represents one of the ways in which Shell sought to combat the limitations of its culture by giving its stakeholders increased access to the company.

In terms of the organizational identity dynamics model, we claim that dysfunctional identity dynamics such as occurred in the case of Shell result when identity construction processes approach total reliance on reflecting and expressing (shown in the left half of figure 3). That is, organizational members infer their identity on the basis of how they express themselves to others and, accordingly, reflect on who they are in the shadow of their own self-expressions. What initially might appear to be attempts at impressing outsiders via projections of identity, turn out to be expressions of cultural self-understanding feeding directly into reflections on organizational identity that are mistaken for outside images. Even though organizational members may espouse concern for external stakeholders as part of their cultural self-expression processes ("Our company is dedicated to customer service!"), they ignore the mirroring process by not listening to external stakeholders and this leads to internally-focused and self-contained identity dynamics. As in the case of Shell, we see that when companies ignore very articulate and media-supported stakeholders, as did Shell for a substantial period of time, they will not be able to accurately assess the impact of influential external images on their identity nor anticipate their lasting effect on their organizational culture. 
Following Brown (1997; Brown \& Starkey 2000) we diagnosed the condition of being unwilling or unable to respond to external images as organizational narcissism. Based on Freud, Brown claimed that narcissism is a psychological response to the need to manage self-esteem. Originally an individual concept, Brown (1997:650) justified its extension to organizations on the basis of a collective need for self-esteem:

... organizations and their subgroups are social categories and, in psychological terms, exist in the participants' common awareness of their membership. In an important sense, therefore, organizations exist in the minds of their members, organizational identities are parts of their individual members' identities, and organizational needs and behaviors are the collective needs and behaviors of their members acting under the influence of their organizational self-images.

Brown then defined narcissism in organizations as a psychological complex consisting of denial, rationalization, self-aggrandizement, attributional egotism, a sense of entitlement and anxiety. While noting that a certain amount of narcissism is healthy, Brown (1997:648) claimed that narcissism becomes dysfunctional when taken to extremes:

Excessive self esteem ... implies ego instability and engagement in grandiose and impossible fantasies serving as substitutes for reality.

Or, as Brown and Starkey (2000: 105) explained:

... overprotection of self-esteem from powerful ego defenses reduces an organization's ability and desire to search for, interpret, evaluate, and deploy information in ways that influence its dominant routines.

As Schwartz $(1987 ; 1990)$ argued on the basis of his psychodynamic analysis of the Challenger disaster, when taken to extremes, organizational narcissism can have dire consequences.

In terms of the model presented in figure 3, a narcissistic organizational identity develops as the result of a solipsistic conversation between identity and culture in which feedback from the mirroring process is ignored, or never even encountered. No real effort is made to communicate with the full range of organizational stakeholders or else communication is strictly unidirectional (emanating from the organization).

A related source of dysfunctional identity dynamics occurs when organizations mistake self-referential expressions (i. e., culturally embedded reflections on identity) for impressions projected to outsiders. Christensen and Cheney (2000:247) diagnosed this dysfunction as organizational self-absorption and self-seduction leading to an "identity game": 
In their desire to be heard and respected, organizations of today participate in an ongoing identity game in which their interest in their surroundings is often overshadowed by their interest in themselves.

They argue that organizations in their eagerness to gain visibility and recognition in the marketplace become so engaged in reflections about who they are and what they stand for that they loose sight of the images and interests of their external stakeholders. Instead, they act on tacit assumptions based in their culture, such as that their stakeholders care about the organization's identity in the same way that they do.

Large corporations and other organizations have become so preoccupied with carefully crafted, elaborate, and univocal expressions of their mission and 'essence' that they often overlook penetrating questions about stakeholder involvement.

Christensen and Askegaard (2001: 297) point out, furthermore, that organizational self-absorption is exacerbated by a

cluttered communication environment, saturated with symbols asserting distinctness and identity ... [where] ... most people today only have the time and capacity to relate to a small fraction of the symbols and messages produced by contemporary organizations.

These researchers claim that stakeholders only rarely care about who the organization is and what it stands for. When organizational members are absorbed within self-referential processes of expressing who they are and reflecting about themselves, external stakeholders simply turn their attention to other, more engaging organizations. Their violated expectations of involvement and of the organization's desire to adapt to their demands then cause disaffected stakeholders to withdraw attention, interest and support from companies that they perceive to be too self-absorbed.

We find such self-absorption not only at the level of organizations such as was illustrated by the Shell-Greenpeace case, but also at the industry level. For example, we believe that industry-wide self-absorption is beginning to appear in the telecommunications industry where companies are constantly struggling to surpass each other and themselves with ever more sophisticated and orchestrated projections of their identity. While their actions seem to be based on their belief that stakeholders care about their self-proclaimed distinctiveness, it would seem prudent to test these beliefs with the judicious use of market research or some other means of connecting with the images of organizational "others".

We argue that organizational self-absorption parallels organizational narcissism in that both give evidence of discrepancies between culture and image. Instead of mirroring themselves in stakeholder images, organizational members reflect on who they are based only in cultural expressions and this leads to organizational (or industrial) self-absorption and/or narcissism. In the case of Shell, we believe that this explains the persistence with which Shell ignored its external stakeholders and, by the same token, 
explains the depth of Shell's identity crisis when the external images were finally taken into account (described by Fombrun \& Rindova, 2000). The Shell example, however, illustrates that organizational narcissism is rarely a static condition for organizations. Narcissism or self-absorption might occur for periods of time based in temporary disassociations between image and culture, but the dynamics of organizational identity will either correct the imbalance or contribute to the organization's demise.

\section{Hyper-adaptation}

The obverse of the problem of paying too little attention to stakeholders is to give stakeholder images so much power over organizational self-definition that cultural heritage is ignored or abandoned. Just as a politician who pays too much attention to polls and focus groups may lose the ability to stand for anything profound, organizations may risk paying too much attention to market research and external images and thereby lose the sense of who they are. In such cases cultural heritage is replaced by exaggerated market adaptations such as hyper-responsiveness to shifting consumer preferences. We argue that ignoring cultural heritage leaves organization members unable to reflect on their identity in relation to their assumptions and values and thereby renders the organization a vacuum of meaning to be filled by the steady and changing stream of images that the organization continuously exchanges with its stakeholders. This condition can be described as the restriction of organizational identity dynamics to the right side of the model shown in figure 3. Loss of organizational culture occurs when the processes of mirroring and impressing become so all-consuming that they are disassociated from the processes of reflecting and expressing depicted in the left half of the figure

Alvesson (1990:373) argued that "development from a strong focus on 'substantive' issues to an increased emphasis on dealing with images as a critical aspect of organizational functioning and management" is a "broad trend in modern corporate life". Although he did not define the shift form "substance to image" as contributing to organizational dysfunction, we find in his article evidence of the kind of selfcontained identity dynamics depicted on the right side of our model. According to Alvesson (1990:377):

An image is something we get primarily through coincidental, infrequent, superficial and/or mediated information, through mass media, public appearances, from second-hand sources, etc., not through our own direct, lasting experiences and perceptions of the 'core' of the object.

According to Alvesson, the conditions under which image replaces substance are produced by distance (geographical or psychological) from the organization and its management which in turn is created by organizational size and reach, by its use of mass communication and other new technologies, and by the abstractness of the expanding 
service sector of the globalizing economy. When image replaces substance, "the core" of the organization (its culture) recedes into the distance, becoming inaccessible.

Alvesson's thesis was that when managers become concerned with the communication of images to stakeholders their new emphasis replaces strong links they formerly maintained to their organization's cultural origins and values and this ultimately leads them to become purveyors of non-substantial (or simulated) images. In his view, such organizations become obsessed with producing endless streams of replaceable projections in the hope of impressing their customers. In relation to our model, Alvesson points to some of the reasons why culture and image become disassociated arguing that image replaces culture in the minds of managers which leads to loss of culture. However, while he states this as an increasingly "normal condition" for organizations, we conceptualize loss of culture as dysfunctional, questioning whether companies can remain reliable and engaging to their stakeholders over time without taking advantage of their culture's substance.

We acknowledge that periods of loss of organizational culture may be on the increase for many organizations as become more and more invested in "the culture of the consumer". This position has been forcefully argued by Du Gay (2000:69) who claimed that: "the market system with its emphasis on consumer sovereignty provides the model through which all forms of organizational relations [will] be structured". Following Du Gay we argue that, when market concerns become influential determinants of the internal structures and processes that organizations adopt, they will be vulnerable to the loss of their organizational culture.

We find a parallel to the processes by which companies lose the point of reference with their organizational culture in the stages of the evolution of images that Baudrillard (1994) described in his book Simulacra and Simulation. In stage one, the image represents or stands in for a profound reality and can be exchanged for the depth of meaning the image (or sign) represents. In stage two, the image acts as a mask covering the profound reality that lies hidden beneath its surface. In stage three, the image works almost alone, in the sense that it masks not a profound reality, but its absence. Finally, in stage four, the image bears no relation whatsoever to reality. There is neither reference nor representation. The image becomes "its own pure simulacrum”. In Baudrillard's (1994: 5-6) words:

Such is simulation, insofar as it is opposed to representation. Representation stems from the principle of equivalence of the sign and of the real (even if this equivalence is utopian, it is a fundamental axiom). Simulation, on the contrary, stems from the utopia of the principle of equivalence, from the radical negation of the sign as value, from the sign as the reversion and death sentence of every reference. Whereas representation attempts to absorb simulation by interpreting it as a false representation, simulation envelops the whole edifice of representation itself as a simulacrum.

In our terms, stage four of the evolution of images, the relationship between images and their former referents is broken - images no longer represent cultural 
expressions, but become self-referential attempts to impress others in order to seduce them. As an example of this development, Eco (1983:44) offered his interpretation of Disneyland where you are assured of seeing "alligators" every time you ride down the "Mississippi". Eco claimed this would never happen on the real Mississippi rendering the Disney experience a "hyper-reality".

Whereas Baudrillard used his argument to celebrate what Poster called "the strange mixture of fantasy and desire that is unique to the late twentieth century culture" (Poster 1988:2) for us, Baudrillard's argument that reality gives way to hyper-reality is a way to understand the disassociation between culture (we claim culture is a referent) and image that transforms identity into simulacrum. In terms of our identity dynamics model, identity is simulated when projections meant to impress others have no referent apart from their reflections in the mirror, that is, when the organizational culture that previously grounded organizational images disappears from view. In their attempt to manage the impressions of others, organizational members take these images to be the only or dominating source for constructing their organization's identity. This implies that images are taken by the organizational members to be the organizational culture and it no longer occurs to them to ask whether image represents culture or not.

In spite of the seductiveness of the seduction argument, we believe its proponents go too far. It is our contention that access and exposure mitigate against organizational identity as pure simulacra by re-uniting culture and images, or at least by spotlighting a lack of connection between cultural expressions and projected images. Just as stakeholders will turn away from extremely self-absorbed, narcissistic organizations, so we believe they will find they cannot trust organizations whose identities are built on image alone. On the margins, some organizations will thrive from the entertainment value of having a simulated identity (what will they think of next?), but the need to support market exchanges with trust will pull most organizations back from pure simulacra.

Thus, for example, in their eagerness to please consumers, organizations may think they can credibly project any impression they like to consumers, no matter what their past heritage holds. And, for a time, bolstered by clever marketing they may get away with being unconcerned with their past and what the company stood for a year ago to their employees or consumers. But, at other times, market researchdefined consumer preferences will not overshadow the same stakeholders' desires to connect with the organization's heritage. This happened when consumers protested the introduction of New Coke in spite of the fact that the world's most careful market research had informed the company of a need to renew its brand. The research led the Coca Cola Company to neglect the role played by cultural heritage and underestimate its importance to consumers who saw the old Coke as part of their lives. Other illustrations of organizations losing their cultural heritage only to seek to regain it at a later time come from recent developments in the fashion industry. Companies such as Gucci, Burburry and most recently Yves Saint Laurent lost their cultural heritage in the hunt for marketshare that led them to hyper-adaptation. But those same companies have re-discovered (and to some extent reinvented) their cultural heritage and 
this reconnection with their cultures has allowed them to re-establish their once strong organizational identities.

As was the case with organizational narcissism, we are not arguing that loss of culture is a permanent condition for organizations. Rather culture loss represents a stage in identity dynamics that can change, for example, either by the effects of organizational exposure or by giving stakeholders greater access to the organizational culture that lies beyond the shifting images of identity claims. Examples of such correctives are found, for example, where companies create interactive digital communities for their consumers to be used for impression management purposes, only to discover that interactivity also raises expectations of access to the organizational culture and provokes many consumers to question the company about the alignment between its projected images and its less intentional cultural expressions.

\section{Conclusions}

We began this paper by pointing out how increasing levels of organizational access and exposure to stakeholders contribute to the need to theorize about organizational identity and how these current trends give theories of organizational identity dynamics enormous practical value. We then located the academic theorizing about organizational identity in the works of Cooley, Mead and Goffman, whose ideas are considered foundational to the social identity theory on which most organizational identity research is based. In this context we developed organizational analogues to the "I" and the "me" proposed by Mead. On the basis of the reasoning derived from Cooley, Mead and Goffman, and from others who have used their work to develop organizational identity theory, we offered a process-based theory of organizational identity dynamics. We concluded with consideration of the practical implications of our model by examining two dysfunctions that can occur in organizational identity dynamics when the effects of access and exposure are denied or ignored. We argued that these dysfunctions either leave the organization with culturally self-referential identity dynamics (leading to organizational narcissism), or overwhelmed by concern for their image (leading to hyper-adaptation).

We believe that this paper contributes to organizational identity theory in three important respects. First, finding analogues to Mead's "I" and "me" adds to our understanding of how social identity theory underpins our theorizing about organizational identity as a social process. By defining these analogies we claim to have made an important, and therefore overlooked, link to the roots of organizational identity theory. Second, the paper provides a strong argument for the much-contested claim that identity and culture not only can be distinguished conceptually, but must both be considered in defining organizational identity as a social process. Finally, by articulating the processes that connect organizational culture, identity and image, we believe our theory of organizational identity dynamics offers a substantial elaboration of what it means to say that identity is a social process. 
In a practical vein, it is our view that knowing how organizational identity dynamics works helps organizations to avoid organizational dysfunction and thus should increase their effectiveness. Based on the implications we see in our model, organizations should strive to nurture and support the processes relating organizational culture, identity and images. An understanding of both culture and images is needed in order to encourage a balanced identity able to develop and grow along with changing conditions and the changing stream of people who associate themselves with the organization. This requires organizational awareness that the processes of mirroring, reflecting, expressing and impressing are part of an integrated dynamic in which identity is simultaneously shaped by cultural understandings formed within the organization and external images provided by stakeholders. This, in turn, requires maintaining an open conversation between top managers, organizational members and external stakeholders, and keeping this conversation in a state of continuous development where all those involved remain willing to listen and respond. We know that this will not be easy for most organizations, however we are convinced that awareness of the interrelated processes of identity dynamics is an important first step.

\section{References}

Albert, S. and Whetten, D. A. (1985) “Organizational identity”; in L. L. Cummings and M. M. Staw (eds.) Research in Organizational Behavior, Greenwich CT: JAI Press, 7: 263-295.

Alvesson, M. (1990) “Organization: From substance to image?”, Organization Studies, 11: 373-394.

Ashforth, B. E. and Mael, F. (1989) "Social identity theory and the organization”, Academy of Management Review, 14: 20-39.

Baudrillard, J. (1994) Simulacra and simulation (trans. S. F. Glaser), Ann Arbor: The University of Michigan Press.

Berg, P. O. and Kreiner, K. 1990. "Corporate architecture: Turning physical settings into symbolic resources", in P. Gagliardi (ed.) Symbols and artifacts: Views of the corporate landscape, Berlin: Walter de Gruyter, pp. 41-67.

Brewer, M. B. and Gardner, W. (1996) "Who is this 'we'?”: Levels of collective identity and self-representations.", Journal of Personality and Social Psychology, 71: 83-93.

Brown, A. D. (1997) “Narcissism, identity, and legitimacy.", Academy of Management Review, 22: 643-686 .

Brown, A. D. and Starkey, K. (2000) “Organizational identity and learning: A psychodynamic perspective”, Academy of Management Review, 25: 102-120.

Cheney, G. and Christensen, L. T. (forthcoming) "Organizational Identity at issue: Linkages between "internal" and "external" organizational communication"; in Jablin, F. M. and Putnam, L. L. (eds.), New Handbook of Organizational Communication, Newbury Park: Sage.

Christensen, L. T. and Askegaard, S. (2001) “Corporate identity and corporate image revisited.”, European Journal of Marketing 35: 292-315.

Christensen, L. T. and Cheney, G. (2000) "Self-absorption and self-seduction in the corporate identity game”, in Schultz, M., Hatch, M. J. and Larsen, M. H. (eds.) The expressive organization: Linking identity, reputation, and the corporate brand, Oxford: Oxford University Press, pp. 246-271.

Cheney, G. and Christensen, L. T. (2001) "Organizational Identity at issue: Linkages between "internal" and "external" organizational communication"; in Jablin, F. M. and Putnam, L. L. (eds.), New Handbook of Organizational Communication, Newbury Park: Sage, pp. 231-69. 
Collingwood, R. G. (1958) The principles of art, New York: Oxford University Press.

Cooley, C. H. (1902/1964) Human nature and the social order, New York: Schocken.

Croce, B. (1909/1995) Aesthetic as science of expression and general linguistic (trans. D. Ainslie), New Brunswick: Transaction.

Czarniawska, B. (1992) Exploring complex organizations: A cultural perspective, Newbury Park CA: Sage.

Czarniawska, B. (1997) Narrating the organization: Dramas of institutional identity, Chicago: University of Chicago Press.

Deephouse, D. L. (2000) "Media reputation as a strategic resource: An integration of mass communication and resource-based theories", Journal of Management, 26.

Dewey, J. (1934) Art as experience, New York: Capricorn Books.

Dickie, G. (1997) Introduction to aesthetics: An analytic approach, New York: Oxford University Press.

Dowling, G. R. (2001) Creating corporate reputations: Identity, image, and performance. Oxford: Oxford University Press.

Du Gay, P. (2000) "Markets and meanings: Re-imagining organizational life", in (Schultz, Hatch \& Holten Larsen, eds.) The Expresssive Organization, Oxford: Oxford University Press, pp. 66-77.

Dutton, J. and Dukerich, J. (1991) "Keeping an eye on the mirror: Image and identity in organizational adaptation", Academy of Management Journal, 34: 517-554.

Dutton, J., Dukerich, J. and Harquail, C. V. (1994) “Organizational images and member identification", Administrative Science Quarterly, 39: 239-263.

Eco, U. (1983) Travels in hyperreality (trans. W. Weaver). San Diego: Harcourt Brace Jovanovich.

Fiol, C. M., Hatch, M. J. and Golden-Biddle, K. (1998) "Organizational culture and identity: What's the difference anyway?"; in Whetten, D. and Godfrey, P. (eds.) Identity in Organizations. Building theory through conversation, Thousands Oaks: Sage Publications, pp. 56-59.

Fombrun, C. (1996) Reputation: Realizing value from the corporate image, Harvard Business School Press, Boston. MA.

Fombrun, C. and Rindova, V. (2000) "The road to transparency: Reputation management at Royal/Dutch Shell"; in Schultz, M., Hatch, M. J. and Holten Larsen, M (eds.) The expressive organization: Linking identity, reputation and the corporate brand, Oxford: Oxford University Press, pp. 77-91.

Ginzel, L. E., Kramer, R. M. and Sutton, R. I. (1993) "Organizational impression management as a reciprocal influence process: The neglected role of the organizational audience”, Research in Organizational Behavior, 15: 227-266.

Gioia, D. A. (1998) In Whetten, D. and Godfrey, P. (eds.) Identity in Organizations. Building theory through conversations, Thousands Oaks. Sage Publications, pp. 17-31.

Gioia, D. A, Schultz, M. and Corley, K (2000) Organizational identity, image and adaptive instability in Academy of Management Review 25: 63-82.

Gioia, D. A. and Thomas, J. B. (1996) Identity, image and issue interpretation: Sensemaking during strategic change in academia, Administrative Science Quarterly, 41: 370-403.

Goffman, E. (1959) The presentation of self in everyday life, New York: Doubleday.

Hatch, M. J. (1993) "The dynamics of organizational culture", Academy of Management Review, 18: 657$-693$.

Hatch, M. J. and Schultz, M. 1997. "Relations between organizational culture, identity and image", European Journal of Marketing, 31: 356-365.

Hatch, M. J. and Schultz, M. S. (2000) "Scaling the Tower of Babel: Relational differences between identity, image and culture in organizations", in Schultz, M., Hatch, M. J. and Larsen, M. H. (eds.) The expressive organization: Linking identity, reputation, and the corporate brand, Oxford University Press, pp. 13-35.

Jenkins, R. (1994) "Rethinking ethnicity: Identity, categorization and power", Ethnic and Racial Studies, 17: 197-223.

Jenkins, R. (1996) Social Identity, London: Routeledge. 
Krefting, L. A. and Frost, P. J. (1985) "Untangling webs, surface waves, and wildcatting", in P. J. Frost, L. F. Moore, M. R. Louis, C. C. Lundberg and Martin, J. (eds.) Organizational Culture, Beverly Hills, CA: Sage, pp. 155-168.

Mead, G. H. (1934) Mind, self and society, University of Chicago Press.

Olins, W. (1989) Corporate identity, Boston: Harvard Business School Press.

Pfeffer, J. (1981) "Management as symbolic action"; in L. L Cummings and Staw, B. (eds.) Research on organizational behavior, Greenwich. JAI Press, 3, pp. 1-52.

Pratt, M. G. and Rafaeli, A. (1997) "Organizational dress as a symbol of multilayered social identities.", Academy of Management Journal, 40: 862-898.

Poster, M. (1988) "Introduction", in M. Poster (ed) Jean Baudrillard. Selected writings 1-9, Stanford: Stanford University Press.

Rafaelli, A. and Pratt, M. G. (1993) "Tailored meanings: On the meaning and impact of organizational dress", Academy of Management Review, 18: 32-55.

Rindova, V. and Fombrun, C. (1998), in D. Whetten and P. Godfrey (eds.), Identity in organizations: Developing theory through conversations. Thousand Oaks, CA: Sage, pp. 59-66.

Rosen, Michael (1988) "You asked for it: Christmas at the bosses' expense", Journal of Management Studies 25: 463-480.

Schein, E. H. (1992) Organizational culture and leadership, 2nd edition, San Francisco: Jossey-Bass.

Schein, E. H. (1985) Organizational culture and leadership,1st edition, San Francisco: Jossey-Bass.

Schultz, Majken (1991) "Transitions between symbolic domains in organizations", Organizational studies 12.

Schwartz, H. S. (1987) "On the psychodynamics of organizational disaster: The case of the space shuttle Challenger",Columbia Journal of World Business, 22(1): 59-67.

Schwartz, H. S. (1990) "The symbol of the space shuttle and the degeneration of the American dream"; in P. Gagliardi (ed.), Symbols and artifacts: Views of the corporate landscape, New York: Aldine de Gruyter, pp. 303-322.

Scruton, R. (1997). The aesthetics of music, Oxford: Clarendon Press.

Tajfel, H. and Turner, J. C. (1979) "An integrative theory of intergroup conflict", in W. G. Austin and S. Worchel (eds.), The social psychology of intergroup relations, Monterey CA: Brooks/Cole, pp. 7-24.

Tedeshi, J. T. (ed.) (1981) Impression management theory and social psychological research, New York: Academic Press.

Whetten, D. and Godfrey, P. (eds.) (1998) Identity in Organizations. Building theory through conversations, Thousands Oaks. Sage Publications. 
